\title{
Musicalidade e êxtase: experiência sensorial em Deliverance de Alexander McQueen
}

\author{
Musicality and excitement: sensory experience in Alexander \\ McQueen's Deliverance
}

FIGUEREDO, Henrique Grimaldi

Universidade Federal de Juiz de Fora - UFJF I henriquegrimaldi@hotmail.com

ALMEIDA, Thamara Venâncio de

Universidade Federal de Juiz de Fora - UFJF I thamaravenancio@live.com

\begin{abstract}
Resumo
Partindo do pressuposto de um ato-desfile como imagem, este artigo promove uma genealogia dos processos de artificação da moda, isto é, sua expressão como valor artístico em detrimento de puro valor mercadológico. Para tanto, elenca-se o desfile Deliverance do britânico Alexander McQueen, no qual a imagem artificada irá assumir-se como imagem sonora para coordenar o potencial comunicativo da performance-desfile.
\end{abstract}

Palavras-chave: Musicalidade. Performance. Alexander McQueen. Artificação.

\section{Abstract}

Starting from the assumption that a fashion show may be considered as images, this paper provides a genealogy of processes of fashion artification, that is, the fashion expression as artistic value rather than a mere marketing tool. To this end, we analyze the Deliverance fashion show by British designer Alexander McQueen, in which the artificated image is transformed in sound image as means to manage the communicative potential of the showperformance.

Key-words: Musicality. Performance. Alexander McQueen. Artification. 


\section{ARTIFICAC̣ÃO E AGENCIAMENTO ESTÉTICO: A COLEC̣ÃO COMO OBRA}

Talvez uma das empreitadas mais estudadas em relação à imagem no contexto contemporâneo seja seu potencial migratório, sua possibilidade de ser estrangeira em outros campos, e encontrar em tais meios valores e ecos simbólicos igualmente valiosos para sua veiculação como elemento comunicacional. A imagem evapora-se, realiza uma fuga umbrátil do ambiente que a contêm, e, ao migrar, decerto, estipula um frescor que reinaugura campos outros.

Há uma certa simpatia nos círculos teóricos, em discorrer o potencial viajante da imagem como um traço fulcral de uma pós-modernidade, encontrando na ruptura com as narrativas modernas algo de messiânico que explicasse o comportamento desta nova realidade. Será Archer, ao trabalhar a ideia de um pós-moderno global, que afirmará, "tudo já havia sido feito; o que nos restava era juntar fragmentos, combiná-los e recombiná-los de formas significativas" (ARCHER, 2001, p. 156).

Certamente há nesta hipótese algo de vívido e perceptível: a imagem no contemporâneo migra continuamente e promove neste caminho seus muitos agenciamentos. Entretanto, a ruptura traumática tão aprazível aos teóricos da pós-modernidade, pode ser vislumbrada como um traço de distensão de uma agenda já existente, de uma narrativa modernista. O crítico alemão Andreas Huyssen, ao revisar as poéticas de um esgotamento da modernidade, irá trabalhar a possibilidade de um tensionamento dos valores que a constituem. Promove, portanto, um desmonte do pós-moderno global ao revisar seus pontos de colisão, e sugere, em alternativa, a perspectiva de uma modernidade continuada (HUYSSEN, 2014), o remonte desta realidade como uma hipermodernidade, assim chamada pelo filósofo francês Gilles Lipovetsky e Serroy (2015), caracterizada por uma expansão dos atributos da modernidade, isto é, uma exacerbação de seu modo de ser.

No cipoal quimérico destas teorizações, há a percepção de que o hipermoderno inscreve no campo social suas alternâncias e avanços, logo, na pesquisa de Lipovetsky, o hipermoderno global é, por fim, uma teoria social da cultura que vislumbra no acontecimento quantificável e rastreável da sociedade os paradigmas de mudança, isto é, ao encarar o que chama de "ondas de estetização do cotidiano", o autor define a era contemporânea como "transestética", em que os conceitos e objetos já nascem intencionalmente estetizados e imbuídos de um valor superavitário, que é decorrente de seus agenciamentos simbólicos (a artificação, como veremos a seguir, pode ser contemplada, por aproximação, a este procedimento).

A imagem migrante - a imagem como abstração da própria imagem - atualiza a dieta visual do contemporâneo ao fornecer possibilidades 
relacionais diversas, forçando as paredes das disciplinas e construindo pontos de intercessão. É uma lógica do rearranjo, da recombinação geradora de significados outros, cujos ecos evocam uma busca pela semelhança disforme, algo presente no pensamento batailliano no início do século XX. Será Bataille a afirmar que,

\begin{abstract}
"A possibilidade de unir num ponto preciso duas espécies de conhecimento até aqui estranhas uma à outra ou grosseiramente confundidas dava a essa ontologia sua consistência inesperada: o movimento do pensamento se perdia por inteiro, mas por inteiro se reencontrava". (BATAILLE, 1943, p. 11).
\end{abstract}

Esta capacidade "de perturbar o próprio conhecimento, produzindo um conhecimento inaudito, um conhecimento que poderíamos dizer, sem medida comum" (DIDI-HUBERMAN, 2015, p. 52), ratifica a potência da imagem em, ora fundar, ora reordenar as disciplinas, operando para isso, na remodelação através, e a partir, do campo social, isto é, em como compreendemos ou lemos estas imagens através de nossa carga e aprendizado em sociedade.

Ao compreendermos estes novos regimes da visualidade como remontes de uma lógica social expandida, passa-se a atuar através de um movimento de aproximação dos campos. É esse social que de certo modo estabelece uma base operativa comum e gera um avizinhamento possível entre campos diversos. É o momento em que numa teoria social do contemporâneo, uma imagem pode ser lida - sem perder essencialmente seu valor - por uma história social da arte, por uma teoria social da moda, por uma pesquisa sonora e semântica da música; leituras estas que deixam de disputar uma verticalidade para estabelecerem-se em uma possível horizontalidade extensiva: um paradigma que irá compreender estas produções como pertencentes à toda uma cultura visual e não mais associada à uma única disciplina. Assim, a moda cabe largamente nesta nova realidade interacional entre os campos, operando conceitualmente seu remonte simbólico.

Tendemos a olhar a imagem numa medida de rasura, como se nada existisse para além-do-ver; uma desconfiança que advém de uma hierarquização histórica documental, em que, o arquivo e o documento, de algum modo superpõem em credibilidade à imagem. Ao desenvolver sua teoria, o filósofo francês Georges Didi-Huberman, descreve um modo de operação que recupera não apenas a sensualidade da imagem, mas promove, concomitantemente, sua emancipação: a imagem pode existir e atuar em qualquer campo e através desta operação, construir conhecimento ou comunicar conceitos (DIDI-HUBERMAN, 2015).

Em sua concepção, a imagem emancipada de um olhar-leitor associado à uma única disciplina, recobre uma espécie de consciência, dotando-se de 
um diálogo que é ele próprio construtor da realidade. Ao inquirir o que querem as imagens e o que há para além das imagens, Didi-Huberman inaugura uma consciência como potencial migrante, isto é, imagens que permeiam e estipulam trajetórias vívidas sendo igualmente responsáveis pela construção social dos campos e, subsequentemente dotadas de valor investigativo: assim, seguindo a lógica de Georges Bataille, em seu livro "O gaio saber visual", DidiHuberman aceita a possibilidade, por exemplo, de uma fotografia de pés de vacas decepados em um matadouro em La Villete, nos rememorar das pernas das dançarinas saindo de cena, no filme de 1929 de David Butler, Fox Follies (DIDI-HUBERMAN, 2015). Tal metodologia pode ser aplicada à nossa leitura do desfile quanto imagem, de uma coisa que ao ser vista, enceta no público - de acordo com sua carga socialmente vivida - a memória de um outro fato.

Neste artigo exploraremos uma destas viagens possíveis: a migração imagética e sua realização de agenciamentos estéticos na imagem de moda, ou seja, como as imagens construídas pelo estilista britânico Alexander McQueen, podem comunicar algo complexo a partir da combinação entre a memória social de seu público - seu conhecimento escolar, iconográfico e sinestésico - e as imagens escolhidas por ele e que vem dotadas de certos significados.

Na contemporaneidade, há uma identificável inclinação que acena às aproximações entre imagem de arte e imagem de moda'. Tal flirt não é assunto novo: desde as co-criações entre a estilista italiana Elsa Schiaparelli e artistas da vanguarda Surrealista, como Salvador Dalí e Cocteau; passando pelas experimentações vestíveis da corrente futurista italiana; ou ainda às apropriações conceituais impetradas pelo costureiro francês Yves Saint-Laurent das obras de Mondrian, Monet e Gustav Klimt; arte e moda compartilham, numa dada medida, uma coluna vertebral comum. A alteração substancialmente reestruturante advém, contudo, de um momento no contemporâneo que rompe os ciclos da retroalimentação, das citações contínuas de um campo no outro (arte-cita-moda-cita-arte). Ao apagar os liames ontológicos entre as duas disciplinas, a lógica hipermoderna - para utilizar aqui o termo proposto por Lipovetsky - opera o nascimento de "um como o outro", isto é, uma moda que nasce artificada, imbuída de valores semelhantes ao do trabalho artístico.

O antropólogo italiano Massimo Canevacci nos aponta que tais "tendências surgidas com a mescla entre moda e arte na contemporaneidade, [...] ao experimentar fusões entre dois estilos (expressões) é uma marca de comunicação visual pós-dualista" (CANEVACCl, 2010, p. 1). Assim, a moda do britânico Alexander McQueen cabe largamente nesta lógica da fusão, em que 
o minora-se uma compreensão da moda como objeto mercadológico puro e a batiza de um valor outro, isto é, um valor artístico: moda artificada.

A artificação, termo utilizado pela socióloga francesa Roberta Shapiro para explicar este fenômeno que associa imagens não-artísticas com o valor "superior" da arte, seria "a transformação da não-arte em arte" (SHAPIRO, 2007, p. 135); isto é, uma recolocação de um corpus de objetos inicialmente desprovidos de valor artístico sob uma nova ótica, um deslocamento do conceito social de arte para abarcar novos elementos cujo valor está migrando. Ao artificar-se, a moda busca soluções estéticas por avizinhamento ou assujeitamento de áreas limítrofes, deglutindo o que the é necessário para realizar sua comunicação. Afastamo-nos, assim, da moda como produto para vislumbrar neste processo artificador um fenômeno que promove uma genealogia da coleção de moda como obra de arte, possuidora, neste contexto, de um potencial comunicativo que às vezes seria impossível ao primeiro caso, isto é, moda como moda; moda como produto.

A artificação da moda advém do fato de que a "ênfase passou a ser colocada sobre a arte como atividade mais do que como objeto" (SHAPIRO, 2007, p. 140), permitindo, portanto, a transformação do desfile - antes plataforma mercadológica - em espaço de performação, e afastando a lógica individual de análise da roupa: o item isolado, mercantilizado, é minorado, focaliza-se a composição como um todo, a performance como ato artístico.

Metodologicamente, iniciamos esta breve reflexão com a recuperação do conceito de modernidade continuada, evidenciando como esta realidade em constante expansão prevê fenômenos como a artificação. Uma vez considerado - para efeitos desta análise - o desfile como ato artístico, propõem-se algumas considerações sobre o desfile Deliverance (primavera/verão 2004) do criador britânico Alexander McQueen, diagnosticando a atribuição central da música como elemento propulsor e coordenador de todo o ato performático, discutindo para tanto, conceitos como o de psicologia sonora, espacialidade acústica e êxtase. 


\section{MÚSICA E SENSORIALIDADE EM DELIVERANCE}

O britânico Alexander McQueen (1969-2010)², talvez seja um dos criadores contemporâneos a melhor compreender, no contexto de uma moda produzida a partir e como elemento estético artístico, a capacidade operacional de componentes externos ao campo da moda na elaboração de narrativas outras. Há de algum modo uma aparente recusa inicial da mercantilização pura do objeto, e, ademais, um esgotamento de suas próprias características constitutivas. Se para a moda a roupa perde seu poder simbólico, não pelo desgaste físico do material, mas por uma obsolescência programada que alimenta o sistema (SUDJIC, 2010), na criação de McQueen o processo invertese. A roupa desprovida de sua função como mercadoria, tem sua cotação mantida por tempo indeterminado ao deslocar-se o valor simbólico da matéria para o processo, para o evento, afinal, "o pressuposto elementar da artificação é o da crença no valor superior da arte" (SHAPIRO, 2007, p. 137).

A curadora Ginger Gregg Duggan, ao refletir sobre a remodelação contemporânea do desfile, encontrará em McQueen o exercício do que chama de "desfile espetáculo" (DUGGAN, 2002). Para Duggan, há no desfile espetáculo uma função narrativa que aproxima-se do teatro, ou ainda da arte performática, traduzindo a passarela em um novo espaço de performação e ressignificando os demais itens (a roupa, as modelos, os cenários), em medium para a extenuação de um propósito estético. Portanto, ao conceber o evento como fim, elementos anteriormente secundários assumem um posicionamento central no ato-desfile, ratificando seu estranhamento ao reposicionar o valor de fundo (a trilha sonora, por exemplo), como primeiro plano, estrutura cêntrica da performance a ser apresentada.

Em Deliverance (primavera/verão 2004), reorganiza-se o modus operandi do campo da moda ao postular a música como a gênese do atoperformance: a roupa e sua venda deixam de ser centrais - ainda encontra-se presente - mas seu fim é outro; é mostrar e comunicar algo novo através do desfile, assumindo, portanto, a música e a sonoridade como aspectos centrais da performance, aquilo que não só possibilita, mas que também coordena todo o acontecimento. Assim, remove-se a essência da roupa como matriz da ação, transubstanciando-a em estrutura de apoio à encenação (WATT, 2012).

2 O designer de moda britânico Alexander McQueen, falecido em 2010, foi responsável, nos anos 1990, por propor um novo tipo de moda cujo nascimento ocorre de forma híbrida (artemoda), sua agressividade estética e sua pesquisa plástica por modelos de desfiles expandidos - cujo objetivo era mais comunicacional e menos mercadológico - levam-no a ser classificado por muitos teóricos da moda como um estilista-artista ou ainda como estilista conceitual. Suas experimentações extremas lhe renderam o título de enfant-terrible (criança terrível) pela imprensa especializada. 
Ao conceber desta forma o ato, a ferramenta de análise em Deliverance será proveniente da teoria sensorial da música e não mais de uma reflexão social da moda; algo tipicamente pensado, como a já discutida aqui, semelhança disforme batailliana.

Tendo como gatilho o filme "They shoot horses, don't they?" (1969) (Imagem 1) do diretor norte-americano Sydney Pollack, que poetizava sobre as maratonas de dança nos Estados Unidos durante a depressão econômica na década de 1930, Deliverance contou com coreografia do escocês Michael Clark e a participação do grupo de dança Les Child. Em uma apresentação repartida em três partes e totalizando quase vinte minutos, o jazz e o blues - tipos musicais comuns aos bares clandestinos no período da Lei Seca norte-americana -, são mesclados a ritmos contemporâneos e transformados nos elementos centrais da apresentação, convergindo visualidade e sonoridade como manifestações sensoriais compostas (WATT, 2012).

Imagem 1 - Frame do filme "They shoot horses, don't they?", de Sydney Pollack

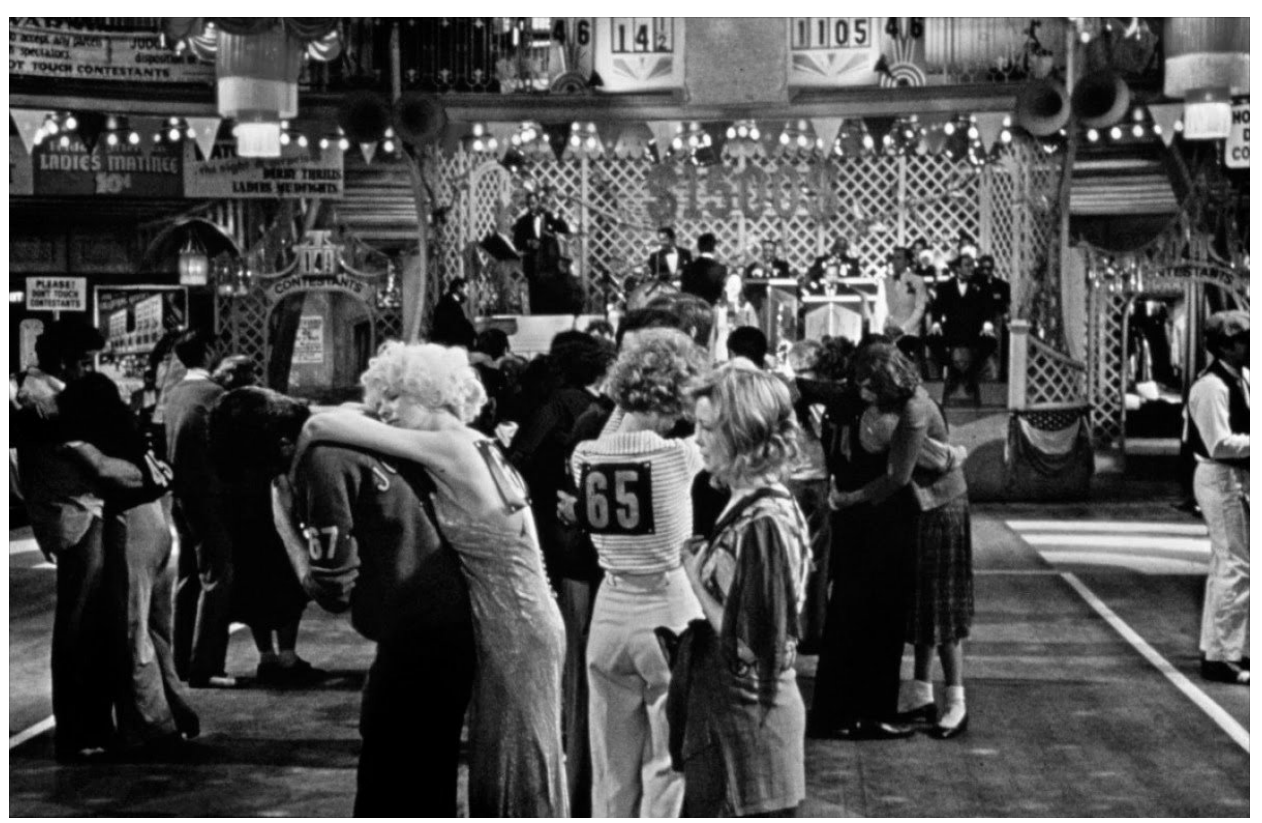

Fonte: captado pelo próprio autor.

Há aqui certos ecos correspondentes à SoundArt, desenvolvida a partir da década de 1970, como as instalações da alemã Helga de la Motte-Haber, cujos trabalhos, segundo o teórico do som, Schulz (2002), estabelecem a consciência de que o sentido da escuta é que fornece ao espaço visual sua qualidade plástica. Portanto, Deliverance opera em sua afluência sensorial, a conformação de um espaço sonoro, ou ainda, as soundscapes (paisagens sonoras), que Schafer ${ }^{3}$ (1993) irá descrever como a potencialidade do espaço

3 O teórico e músico canadense Ray Schafer discorre sobre a ideia de paisagem sonora (soundscapes); aqui utilizamos seu conceito para entender o desfile-performance de McQueen como um lugar em que há certa simultaneidade entre espaço físico e espaço sonoro, sendo de algum modo inseparáveis e responsáveis pela plasticidade e sensorialidade da ação. 
acústico na incisão sensorial do sujeito. Distendendo a tradição da arte sonora - majoritariamente uma arte de instalação - esse desfile irá conceber o espaço acústico como palco, mas ao manter a efemeridade da moda, focaliza a performance como uma saída da instalação. Logo, para além das paisagens sonoras schaferianas, há outras questões substanciais que irão estabelecer perspectivas relacionais entre os atores e seu público, ratificando, mais que uma espacialidade sonora, uma incisão do som no próprio sujeito e distintas modalidades de recepção.

Sobre a percepção do som e seus desdobramentos sensoriais no sujeito, a discussão de dois pontos torna-se pertinentes: a ideia de objeto sonoro na psicanálise freudiana; e questões funcionais da psicologia cognitiva ou sonora. Deliverance busca captar vetores-força, isto é, inculcar através do som algum desconforto sensorial no sujeito. Apesar de um certo eixo narrativo na dança, a música que a rege fundamenta-se numa montagem caótica, sem instantes de transição evidentemente elaborados, e, incorporando os nãosons, os silêncios (talvez uma referência à experimentação do compositor e artista sonoro americano John (age), como ponte ou mote do ritmo seguinte (WATT, 2012). Nesse processo reside um evidente desconforto, sentido tanto no público, que fica em estado de espera ou latência sem realmente saber se a apresentação foi finalizada, quanto nos dançarinos, cujos corpos cambaleantes estão metaforicamente presos à regência do som.

Essa dependência da música como amarra da performance associase num instante primevo e inconsciente a um objeto sonoro. $\mathrm{Na}$ antropologia cultural, a moda é muitas vezes discutida sob a ótica de uma manifestação primitiva de significação corporal, reincidindo no simbólico a partir de um sistema de representação pré-verbal (BLACKING, 1977). Ao colidirmos tal teoria com os estudos freudianos da musicalidade da fala, percebemos um eixo comum: a essência da música e da moda como composições comunicativas que transcendem a fala, ou que orbitam anteriormente à fala. Ao verificar tais reflexões no pensamento freudiano, o estudioso da teoria psicanalítica, Cláudio Munayer David afirma que:

Os lapsos de linguagem e os chistes podem exemplificar a força das representações sonoras, entretanto, a musicalidade da fala ainda excede às representações fonéticas. As imagens sonoras, como um pensamento musical, também representam seu sentido não verbal. O sotaque particular de um pensamento reflete algo das escolhas do pensador, de sua intenção, de seu estado afetivo, de seu contexto sociocultural, deslocando e condensado o sentido de um discurso. Esses padrões sonoros constituemse em ressonâncias pulsionais que se apresentam como distorções na cadeia de significantes. (DAVID, 2006, p. 108) 
Portanto, o que o objeto sonoro psicanalítico nos forneceem Deliverance é exatamente este instante pré-verbal, cuja narrativa sonora, idealmente pensada por McQueen, terá um efeito particular em cada um de seus observadores, efeito este que advém de uma tradição do pensamento individual, dos formatos de criação do sujeito, de sua carga simbólica cultural. A mensagem é elaborada sob uma percepção, mas quando viaja até seu receptor - o público - sofrerá associações semióticas constantes e inumeráveis. Não seria exagero identificar em Deliverance (Imagem 2) uma possível tanatofilia ${ }^{4}$, que opera como pulsão de morte, e simultaneamente um certo sadismo. Nos três atos que compõem a performance, a música alta e enérgica já denota a proposta do projeto, a estética do esgotamento: modelos dançando até a exaustão física, de forma ágil e compulsória, corpos suados e cambaleantes dos que competem - aqui talvez resida esse desejo de morte, essa vontade de se dançar até a morte ou no post-mortem, como nas alegorias das danças macabras no período medieval -, e isto gera no receptor uma dimensão sádica, o testemunho de algo torturante a ser assistido silenciosamente.

Imagem 2 - Momentos de exaustão e êxtase musical em Deliverance.

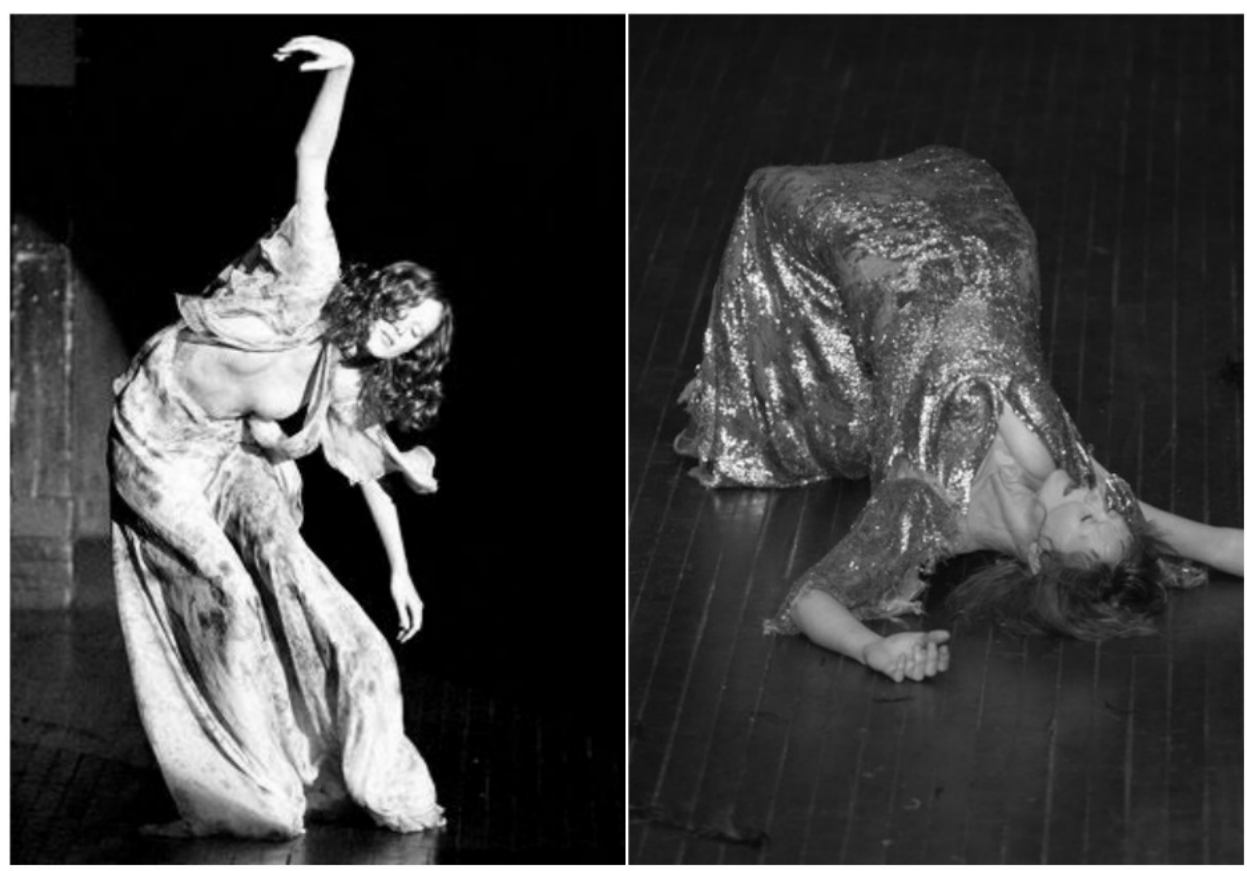

Fonte: Alexander McQueen (2018).

O objeto sonoro freudiano, inerente ao sujeito desde a primeira infância - "[...] os estímulos auditivos são os primeiros a causar grande impacto no comportamento fetal. Aos seis meses de gestação o feto já apresenta reações especificas à voz da mãe, à música [...]" (DAVID, 2006, p. 108) -, será o responsável por elaborar em Deliverance um espaço sonoro que não é apenas material, mas uma memória sonora que transforma aquela experiência em algo individual. A imagem, artificada como música, torna-se movimento sonoro nestes corpos que bailam. A invisibilidade efusiva do som é transferida aos 
corpos por vibração sensorial, uma espécie de pulsão energética que desalinha e agita o sujeito, um movimento que rompe a inércia das cordas (WATT, 2012). Assim, a performance promove uma narrativa particular, ensaiada, editada, contudo, aberta, reincidindo em seus interlocutores narrativas outras, pessoais, imanentes às suas máquinas psíquicas.

Neste ponto encontra-se a confluência entre o objeto sonoro freudiano e a psicologia sonora ou cognitiva, mais especificamente oriunda da Teoria da Emoção de Meyer, fundada em princípios gestálticos. Em sua obra Emotion and Meaning in Music, de 1956, Meyer irá propor que a percepção não provém nem da combinação sonora, nem de um estímulo isolado, mas de estímulos organizados em padrões, cujos significados são essencialmente culturais. Tendo como base a Teoria do Conflito de Dewey, sua tese previa que a partir de uma bagagem passada, um estímulo no presente nos faz esperar uma consequência definida, logo Meyer afirma que:

Significado musical é produto de expectativa. Se, de acordo com nossa experiência passada, um estímulo nos leva a esperar um evento musical consequente mais ou menos definido, então aquele estímulo tem significado [...] Música num estilo com o qual não estamos familiarizados é sem sentido, uma vez que expectativa é um produto de experiência estilística. (MEYER, 1956, p. 35)

O que ocorre em Deliverance é o tensionamento deste processo, uma vez que, há algo do blues e do jazz na memória afetiva ou visual de cada observador do evento, mas o modo como se constrói a proposição, isto é, pervertendo o sentido da música, forçando ou descontruindo as pontes que ligam uma à outra, ou ainda incorporando uma dança extasiática que foge ao esperado, acarreta a inauguração de uma relação nova com aquela já firmada tradição. Ao revisar a Estética Experimental de Berlyne, de 1971, o pesquisador da área musical e de composição, Teixeira dos Santos irá afirma que:

Para Berlyne, a atenção é voltada não somente para a seleção, mas pela intensidade (curiosidade). $\mathrm{Na}$ estética experimental de Berlyne há a proposição de que as propriedades dos estímulos artísticos, como a complexidade e a familiaridade, produzem prazer a partir do nível de excitação do observador. As pessoas geralmente preferem um estado intermediário de excitação. (SANTOS, 2012, p. 71).

Aqui, mais uma vez a apresentação musical em Deliverance prevê uma dilatação da relação mensagem-observador. $\mathrm{O}$ incômodo gerado advém deste estado de excitação que transcende o intermediário. O que está em jogo ali é o momento do êxtase, da construção dionisíaca do sentir, algo que se inicia ordenado, mas que em determinado momento - impossível de ser definido 
com precisão - torna-se caótico. Daí a necessidade de analisar o evento como um todo, como se fosse composto por uma única expressão musical e não por diferentes músicas aglomeradas. Não há o momento exato da libertação da excitação, ele apenas ocorre, talvez uma alusão à epidemia de dança de Estrasburgo em 1518, um momento de histeria coletiva ao qual podemos aproximar um possível êxtase, no sentido nietzschiano ${ }^{5}$ (WATT, 2012).

O que buscamos pontuar nesta reflexão, é uma tendência da dieta visual e sensorial do contemporâneo, que em sentido oposto ao purismo, mescla continuamente e de formas novas, áreas muitas vezes já consolidadas e aparentemente irreconciliáveis. Das pesquisas sensoriais da SoundArt, passando brevemente por algumas teorias do campo musical, buscamos compreender um evento que, presumivelmente estrangeiro ao campo da música, mostra-se na realidade, conformado por este. Pela brevidade do texto, nos faltam páginas para aprofundarmos em detalhes o desdobramento e os modos de operação de cada uma das teorias aqui citadas. Contudo, fica claro que, no contexto desta modernidade continuada, estas operações de simbiose tornaram-se cada vez mais numerosas, e nos ferramentam para analisarmos eventos cada vez mais complexos, permitindo, como neste caso em específico, apreender o desfile como uma performance não só mediada pela música, mas completamente dependente desta.

\section{RECORRÊNCIAS}

Em Deliverance, os dançarinos de McQueen são forçados até a exaustão completa, dançam acompanhando o ritmo frenético da música, os corpos sendo continuamente reduzidos pelo cansaço. A musicalidade possui valor central, gerando um outro tipo de imagem, uma imagem sonora. Essa busca por uma imagem sonora - que não é estática, mas continuamente mutável - apresenta uma certa recorrência no trabalho do estilista-artista britânico Alexander McQueen. Diversas outras experiências de passarela assumem esse caráter de performance que possui a música como ponto de ignição e fio condutor da narrativa.

Em Sarabande (primavera/verão 2007) e The Horn of Plenty (outono/ inverno 2009), a música também torna-se crucial, guiando os performers na execução de um ato que, desprovido da composição sonora não possuiria qualquer ritmo ou função visual, um ponto já citado no texto quando recuperamos a teoria de Helga de la Motte-Heber que associa a qualidade visual ao som. O que queremos demonstrar aqui é a recorrência na criação de

5

O filósofo alemão Friedrich Nietzsche defende o aspecto dionisíaco da arte e da música, um estado de letargia ou excitação próximo à embriaguez. O que McQueen propõem em Deliverance é algo semelhante, um imperativo musical como causador da embriaguez sensorial. 
McQueen em apropriar-se do som na elaboração de uma plasticidade visual. Tal fato é perceptível em outros criadores que também são considerados estilistasartistas: Viktor \& Rolf, Hussein Chalayan, Thom Browne, apenas para citar alguns.

Portanto, assumirtais desfiles como uma experiência artificada, einvestigar o uso incisivo do som, faz-se pertinente não apenas em um caso pontual, mas em toda uma gama de criadores que tem pensado a música e suas teorias como peças fundamentais na elaboração de suas narrativas visuais. Na presença deste campo expandido, estarmos abertos a tais influências e suas análises, enriquecem não apenas o campo da moda como também sua correlação com o som, trabalhado quanto composição plástica. Abraçar tais experimentações é perceber uma necessidade de reescrever a cultura como prática social no contemporâneo e cartografar esse jazz composto no desarranjo de nossa realidade. 


\section{REFERÊNCIAS}

ALEXANDER McQUEEN. Disponível em: <https://www.alexandermcqueen. com/countries/index>. Acesso em: 5 jan. 2018.

ARCHER, Michael. Arte contemporânea: uma história concisa. São Paulo: M. Fontes, 2001.

BATAILLE, Georges. La expérience intérieure. Paris: Gallimard, 1943.

BLACKING, John. The antropology of the body. Londres: ASA Monograph 15, 1977.

CANEVACCI, Massimo. Por um mapa antropológico da moda: entrevista. Ciência e Cultura, São Paulo, v. 62, n. 2, 2010.

DAVID, Claúdio Munayer. A musicalidade da fala, o objeto sonoro em Freud. Reverso, Belo Horizonte, ano 28, n. 53, p. 107-112, 2006.

DIDI-HUBERMAN, Georges. A semelhança informe ou o gaio saber visual segundo Georges Bataille. São Paulo: Contraponto, 2015.

DUGGAN, Ginger Gregg. O maior espetáculo da terra: os desfiles de moda contemporânea e sua relação com a arte performática. Fashion Theory, São Paulo, v. 1, n. 2, p. 3-30, 2002.

HUYSSEN, Andreas. Culturas do passado-presente: modernismo, artes visuais, políticas da memória. São Paulo: Contraponto, 2014.

LIPOVETISKY, Gilles; SERROY, Jean. A estetização do mundo: viver na era do capitalismo artista. São Paulo: Companhia das Letras, 2015.

MEYER, Leonard. Emotion and meaning in music. Chicago: Chicago University Press, 1956.

SANTOS, Regina Antunes Teixeira. Psicologia da música: aportes teóricos e metodológicos por mais de um século. Revista Música em Perspectiva, Curitiba, v. 5, n. 1, p. 65-90, 2012.

SCHAFER, Raymond Murray. The soundscape. Rochester: Destiny Books, 1993. 
SCHULZ, Bernd (Org.). Resonances: aspects of sound art. Heidelberg: Kehrer Verlag, 2002.

SHAPIRO, Roberta. Que é artificação? Revista Sociedade e Estado, Brasília, v. 22, n. 1, p. 135-151, 2007.

SUDJIC, Deyan. A linguagem das coisas. Rio de Janeiro: Intrínseca, 2010.

WATT, Judith. Alexander mcqueen, the life and the legacy. New York: Harper Design, 2012. 